\title{
ARTICLE
}

\section{Developmental dyslexia: clinical aspects}

\section{S. Thambirajah}

\begin{abstract}
M. S. Thambirajah is a consultant child and adolescent psychiatrist working in Dudley and Walsall Mental Health Partnership Trust. He is the author of Case Studies in Child and Adolescent Mental Health (Radcliffe Publishing 2007) and Psychological Basis of Psychiatry (Elsevier 2005) and co-author of Understanding School Refusal (Jessica Kingsley Publishers 2007). Correspondence Dr M. S. Thambirajah, Evergreen Place, Walsall CAMHS, 18 Lichfield Street, Walsall, West Midlands WS1 1TJ, UK. Email: ibmaht@hotmail.com
\end{abstract}

\begin{abstract}
SUMMARY
Developmental dyslexia (reading disability) is a specific impairment in learning to read that affects $3-6 \%$ of school children in English-speaking countries. It is overrepresented in clinical populations referred to child and adolescent mental health services because of its high comorbidity with conduct disorder, attention-deficit hyperactivity disorder and other developmental disorders. Clinicians may fail to identify it unless they maintain a high degree of awareness and make specific inquiries. A three-stage approach (routine screening, in-depth examination and referral for further testing) is described. The features of dyslexia and the clues to its diagnosis are discussed. A number of simple tests for identifying it are available and familiarity with these should improve diagnostic accuracy. In addition to treating psychiatric comorbidity, the clinician can help the child by working with educational professionals to ensure that educational needs are met. Evidence-based early interventions are available. Later reading interventions improve reading but rarely bring about normalisation.

\section{DECLARATION OF INTEREST}

None.
\end{abstract}

In my previous article (Thambirajah 2010) I gave an overview of developmental dyslexia, discussing its definition, aetiology, epidemiology and the brain imaging and genetic studies that underlie our current understanding of the disorder. Here, I will focus on clinical aspects of dyslexia.

\section{Comorbidity}

As with other developmental disorders, in dyslexia comorbidity with other childhood disorders is the rule rather than the exception (Box 1). Two types of comorbidity can be identified: other co-occurring developmental disorders and comorbid psychiatric disorders. In addition, emotional problems as consequences of dyslexia are common and may be very disabling.

Developmental disorders that commonly co-occur with dyslexia include specific language impairment (Catts 2005), specific arithmetic disorder (Lewis 1994), developmental coordination disorder (Kaplan 1998) and autism-spectrum disorders (Reitzel 2003). Although precise prevalence rates of comorbidity have not been documented, it is common to find considerable overlap among these disorders. Indeed, some authorities feel that they all have common underlying cognitive impairments and manifest as a continuum or spectrum of disorders (Snowling 2008).

The most common childhood psychiatric disorders reported in dyslexia are conduct disorder and attention-deficit hyperactivity disorder (ADHD). In the Isle of Wight study, one-third of the 10-yearolds with reading disability were reported to have conduct disorder and one-third with conduct disorder were shown to have reading disability (Berger 1975). A number of studies have reported a strong relationship between early reading disability and oppositional behaviour in pre-adolescence and conduct disorder in adolescence (Carroll 2005). The prevalence of dyslexia among youth offenders has been reported to be around 33\% (Williams 1994). Comorbidity with ADHD is in the range of $40 \%$ (Pennington 2005). Genetic research shows that this may be due to shared genetic influence (Willcutt 2000). These and other findings have led to the inclusion of reading and literacy interventions in parent training programmes designed for children with behavioural problems. It should be noted that treatment of ADHD with medication seems to have no effect on reading in those with dyslexia and comorbid ADHD (Willcutt 2000).

BOX 1 Comorbidity in dyslexia

Comorbidity with other specific developmental disorders

- Reading comprehension difficulties

- Specific speech and language impairment

- Developmental coordination disorder

Comorbidity with psychiatric conditions

- Conduct disorder

- Hyperkinetic disorder (attention-deficit hyperactivity disorder)

- Anxiety

Associated problems

- The Matthew effect ('the rich get richer while the poor get poorer')

- Poor self-esteem 
Internalising disorders, especially anxiety, are particularly common in girls with dyslexia (Pennington 2009: p. 48). Dyslexia in children may contribute to school refusal as their literacy problems can make school an unpleasant place (Thambirajah 2008: p 36). A prominent feature of some children with dyslexia is fear of failure, resulting in avoidance of reading. Consequently, they fall further behind in reading. This has been called the Matthew effect in reading (a term borrowed from The New Testament to mean that the rich get richer and the poor get poorer; Stanovich, 1986). The psychological impact of the realisation that they have difficulties with reading can be devastating for children. It can result in chronic frustration, low selfesteem, anxiety and oppositional behaviour. These secondary effects of dyslexia may prompt referral to child and adolescent mental health services (CAMHS). Parents are often concerned about their child's academic underachievement.

\section{Developmental history}

The developmental history of most children with dyslexia is usually unremarkable, although mild speech delays are reported in some. Since dyslexia is a specific developmental disorder, it is generally accepted that development in other areas is normal. The most significant information is to be found embedded in the early development of reading and in educational history. A family history of reading difficulties is a good predictor of dyslexia in the child, but parents may not volunteer this information. Specific enquiries need to made about parents' reading difficulties.

During the pre-school period a history of delayed speech development in early childhood is a marker for dyslexia (Shaywitz 2003a). One of the earliest indications of dyslexia is difficulty in learning names of objects, colours and letters of the alphabet and sounds of letters of the alphabet. Difficulty learning nursery rhymes, slow learning of letters, and difficulty remembering names of letters or failure to know the letters of one's own name are common. Reading problems commonly become noticeable during the first 2 years of schooling (usually at 5 to 6 years of age) and are most prominent during middle childhood (8 to 12 years of age). It is common for children to forget newly learned words because of poor consolidation of short-term phonological memory. Reading is often slow and laboured. As the child grows older, difficulties in copying from the board and poor spelling become common. Learning a second language is particularly difficult. In mathematics, many children show difficulties when numerical problems are presented in written form. In adolescence and adulthood, lack of fluent reading may be the most evident indicator. Slow, laboured reading is the hallmark of dyslexia in older readers. Poor performance on timed tests is common. Children with dyslexia begin to avoid reading from an early age and many show a prominent lack of enjoyment in reading.

\section{Clinical examination}

The three essential features of developmental dyslexia are inaccurate reading, poor spelling and slow reading.

\section{Inaccurate reading}

Reading in dyslexia is characterised by distortions, omissions and substitution of words or parts of words. Irregular words (such as 'island') may be read as regular words (/is/-/land/). Some children with dyslexia have more difficulty reading and spelling common function words ('little words') such as 'the', 'were', 'is' and 'this'. Analysis of reading errors (miscue analysis) is for remedial teaching.

\section{Poor spelling}

Poor spelling is one of the most readily observable signs of dyslexia. However, the reversal of letter orientations ('b' written as ' $d$ ') and letter sequences ('saw' written as 'was') often seen in dyslexia are common in 5-year-olds and they are not significant until the age of 7 or 8 . In general, children with dyslexia make multiple spelling errors. Two types of error are observed: phonetic spelling errors (e.g. 'packet' written as 'pakt') and dysphonetic errors (e.g. 'trumpet' written as 'tlrnfk').

\section{Slow reading}

Slow, laboured reading is a cardinal feature of dyslexia in most children, adolescents and adults. As they grow up, affected children develop compensatory reading strategies and accuracy of reading may improve. But they continue to have decoding difficulties, especially with unfamiliar words, and this slows down their reading. Dyslexic difficulties may be identified only through timed tasks.

\section{Identifying dyslexia}

Although most, if not all, children with dyslexia show the features listed in Box 2, the presentation, severity and the psychological profile of the disorder show considerable individual variation.

\section{BOX 2 Salient clinical features of dyslexia}

$\begin{array}{ll}\text { - Significant impairment in reading } & \text { - 'Unexpectedness' in light of other abilities } \\ \text { attainment } & \text { - Family history of dyslexia } \\ \text { - Poor spelling } & \text { - Poor phoneme awareness } \\ \text { - Slow, laboured reading } & \text { - Poor decoding skills }\end{array}$


BOX 3 Clues to identifying dyslexia

- Extreme difficulty reading grade-level books and words

- Oral performance significantly better than written

- Prominent difficulties with spelling

- Positive family history of reading problems

- Delays in learning the alphabet, names of colours and objects

- Disinclination to read

Identifying reading difficulties is usually straightforward and does not necessarily involve extensive testing, especially in more severe cases. However, in CAMHS the immediacy of the presenting problems (e.g. severe conduct problems) may mask specific developmental disorders unless they are deliberately looked for. A three-step approach to identification is proposed here, which includes initial screening, followed by a more comprehensive assessment and, last and if appropriate, referral for further investigations using standardised psychometric tests.

\section{Initial screening}

This is best carried out while taking a routine developmental history. The history should include enquiries about reading development and speech and language difficulties. A family history of reading difficulties is one of the strongest indicators of dyslexia in a child. Box 3 lists clues to the diagnosis of developmental dyslexia, Box 4 outlines the main screening points, and Box 5 lists useful questions that may be asked of the child or young person.

Asking the child about any difficulties in reading (e.g. copying from the board) may provide useful information. Poor spelling is the 'giveaway' sign in dyslexia. During routine examination, asking the child to do some free writing (on topics such as 'my pet, 'things I like' or 'my best friend') provides an opportunity to assess spelling. The following was written by a boy aged 8 years 9 months:

Scool is a skary plase. Th teacher soutz at me. Kids lauf and say yuar dum. I am not dum. I get mad at tem. Ben makes fun of me. He calld me names and I kickd him under the dsk. Mr Wall tld me oof. Tis is hw I got into troble.

BOX 4 Identifying dyslexia: screening during routine assessment

- Routinely ask specifically about concerns regarding reading and spelling

- Obtain a detailed history of speech and language development

- Obtain a history of any early difficulties with naming (alphabets, colours and objects) and learning nursery rhymes

- Ask the child to do some free writing and note any spelling errors

- Request a school report or teacher account, including reading levels and results of any reading tests or Standard Assessment Test results
BOX 5 Screening questions for dyslexia

- Do you find that you have to read words again and again to get them right?

- Do you find it difficult to read out loud in class?

- Do you read more slowly than others in your class?

- Do you find copying from the board difficult?

- Do you find it difficult getting your ideas down in writing?

- Do you make a lot of spelling mistakes?

(School is a scary place. The teacher shouts at me. Kids laugh and say, 'You are dumb'. I am not dumb. I get mad at them. Ben makes fun of me. He called me names and I kicked him under the desk. Mr. Wall told me off. This is how I got into trouble.)

A school report or teacher's account of level of reading, together with any test results, should be requested. At the end of the screening process, the clinician may have sufficient evidence to decide whether dyslexia is a possibility. If it is, a comprehensive assessment should be carried out.

\section{Comprehensive assessment}

There is no single test for dyslexia. Any assessment of reading ability should involve tests of single-word and non-word reading, spelling and phonological awareness. The clinician may also want to test the level of general intellectual functioning. Box 6 outlines the essential steps for comprehensive clinical assessment.

\section{Single-word reading tests}

These tests contain a list of words of increasing complexity or relative infrequency of use for children to read out loud. The test is discontinued if the child misreads five consecutive words. The child's 'reading age' is calculated from the number of words read correctly. A commonly available test is the Schonell Graded Word Reading Test (Schonell 1950), which is available on a number of websites.

BOX 6 Identifying dyslexia: comprehensive assessment

- Arrange a separate session to carry out a detailed developmental history and examination

- Apply the following tests:

a graded single-word reading test

a test of spelling

a non-word reading test

a simple standardised test of reading efficiency such as the Test Of Word Reading Efficiency (TOWRE) 
A number of standardised word-reading tests with sound psychometric properties are commercially available (Box 7).

\section{Spelling tests}

These consist of lists of words of increasing spelling difficulty. The Schonell Spelling Test (Schonell 1932) is also available on various websites, but its psychometric properties are said to be poor (alternatives are given in Box 7). The child could also be asked to do some free writing, which can be checked for errors.

\section{Non-word reading tests}

These are useful tests of decoding and they tap into the core phonological problems of dyslexia. The child is presented with a list of noon-words, preferably printed on cards, which they have to read aloud. Non-words (pseudowords) resemble ordinary English words, but do not make sense, for example 'wolt', 'pobule', 'fread', 'kettuce'. They are considered to be a good test of decoding skills. The test is discontinued after the child makes five consecutive errors. A number of standardised nonword reading tests are available (Box 7) but the clinician may prefer to compose their own test as a rough guide. A 7-year-old should be able to read one-syllable non-words without difficulty.

\section{Tests of phonological awareness}

Phonological awareness tests involve identification and manipulation of phonemes in words. Phoneme deletion tasks are easy to use in the clinical setting. The clinician reads out words from a list and the child is asked to repeat the word without the first, middle or last phoneme. For example, the child may be asked to repeat the following words without the sound shown in parentheses: (d)raw, (sh)out, lo(ca)tion and so on.

\section{Tests of fluency}

Fluency tests involve timed reading. The Test of Word Reading Efficiency (TOWRE; Torgesen 1999) taps into a number of phonological abilities and is an excellent test for routine clinical examination (Box 7). Other tests such as rapid naming of letters and pictures can also be used.

\section{Referral for standardised assessment of reading}

In some cases referral for standardised tests may be warranted to confirm a suspected diagnosis, especially when the clinical findings are inconsistent or doubtful. There are a number of standardised tests for assessing reading and reading subskills (Box 7). The usefulness of standardised tests lies in the fact that the child's performance can be compared with that of a comparative population (norms). The findings are expressed as standard scores, percentile and age equivalents and are easy to interpret. Many of the tests mentioned in Box 7 do not need specialised training.

\section{Diagnosis}

For a diagnosis of dyslexia to be made, the clinician must first establish that the severity of reading difficulty is significant and persistent. A reading age that is 2 years below the child's chronological age or a standard score 1-1.5 s.d. below the mean on reading tests is usually taken as the cut-off. Second, the clinician must be satisfied that the condition is idiopathic, i.e. that the poor performance in reading and spelling is not due to other identifiable causes.

BOX 7 Standardised instruments for assessment of reading

\section{Single-word reading tests}

Commonly used tests include the Macmillan Graded Word Reading Test (Raban 1985) and the Hodder Oral Reading Tests (Vincent 2006). These include single-word reading, sentence reading and reading speed assessment, for ages 5 to $16+$

\section{Spelling tests}

Vernon's Graded Word Reading Test (Vernon 1998) is a simple test of spelling. In educational settings SPAR Spelling and Reading Tests (Young 1978) are popular.

\section{Non-word reading tests}

Of the many non-word reading tests, perhaps the most commonly used is the Graded Nonword Reading Test (Snowling 1996). This is suitable for 5- to 11 -year-olds and takes 5 minutes to administer. A sample of the test may be found in Snowling \& Stackhouse (2006: p. 112). Another accessible non-word reading test is the Nonword Decoding Test (Turner 2003).

The Test of Word Reading Efficiency

The TOWRE (Torgesen 1999) is unique in that it is a timed test that taps into the two kinds of skills that are critical to reading: the ability to sound out words quickly and accurately and the ability to recognise familiar words by sight. It is suitable for ages 6 to 24 years. It takes only 5 to 10 minutes and provides a rapid and easy way of assessing word-reading and decoding skills for every reading level. It has the added advantage of testing fluency, an important skill especially in older children. For these reasons, the TOWRE is by far the most useful test for clinicians.

\section{Composite tests}

Two composite tests used by psychologists and researchers are the Comprehensive Test of Phonological Processing (CTOPP; Wagner 1999) and the Phonological Assessment Battery (PhAB Frederickson 1997). These consist of batteries of tests of reading subskills and special training is required in their administration. Clinical psychologists also use the reading and spelling subtests in the Wechsler Individual Attainment Test (WIAT-II; Wechsler 2005) or the Wide Range Achievement Test (WRAT-4; Wilkinson 2006).

Tests of general IQ (e.g. Wechsler Intelligence Scale for Children WISC-IV; Wechsler 2003) provide an overall measure of cognitive abilities and are now considered to be unnecessary in diagnosing dyslexia. 


\section{Differential diagnosis}

Dyslexia is not the only form of reading difficulty and not all reading difficulties are due to dyslexia. More children have reading difficulties than have true dyslexia. Differential diagnosis includes the following conditions: organic conditions, intellectual disability, deprivation and poor reading comprehension (Box 8).

\section{Organic conditions}

Some children fail to attain adequate reading levels because of physical conditions. Although many neurological and visual conditions can result in reading failure, it is loss of hearing that most commonly leads to reading difficulties. Recurrent otitis media is of particular importance, as it is common and can cause reduced hearing, compromising the normal learning progress at a critical period in development.

\section{General intellectual disability}

Children with general intellectual disability fail to learn to read, write and spell at the level of their contemporaries, but this is unsurprising given that they are slow to learn everything. The clue to the diagnosis here lies in the level of adaptive functioning.

\section{Deprivation}

Children from low socioeconomic backgrounds and those from deprived, understimulating environments are often behind in reading. An important subgroup of poor readers comprises children under local authority care ('looked after' children), who typically have unstable schooling and disrupted placement histories.

\section{Deprivation}

A group of children with poor reading and comprehension skills (known as 'garden variety' poor readers) have been described (Stanovich 1994). These backward readers are thought to be deprived and poorly motivated with respect to reading; they usually improve with reading instruction.

\section{BOX 8 Differential diagnosis of significant underachievement in reading}

- Visual or neurological impairment

- Hearing difficulties, especially otitis media

- General intellectual disability

- Environmental deprivation (e.g. poor learning environment, 'looked after' children)

- Significant reading comprehension difficulties

- Developmental dyslexia

\section{Reading comprehension difficulties}

Poor comprehension is a relatively common cause of reading difficulties, especially in older children, and it is distinct from dyslexia. The primary difficulty is in understanding what is read rather than in inaccurate reading. It is thought to represent a general language comprehension limitation and overlaps with oral language (speech) disorders. Reading comprehension difficulties are closely related to language difficulties and may co-occur with dyslexia (Stothard 1995).

\section{Life course and prognosis}

Well-designed longitudinal studies indicate that reading deficits seen in dyslexia are generally stable and persist into late adolescence and adulthood. Although both dyslexic and unimpaired readers improve their reading scores as they get older, the gap between the two groups remains. In the Connecticut Longitudinal Study, over 70\% of those identified as having dyslexia in Grade 3 (about 8 years old) remained dyslexic as adults (Shaywitz 1999, 2003b). Even with intensive evidence-based reading interventions, about half the children do not show substantial improvement (non-responders) (Torgesen 2001). Initial severity of dyslexia and general intellectual level seem the most important predictors of later progress.

Viewed from a long-term perspective, dyslexia does not represent a transient lag in development; rather, the reading impairment is persistent, continuing into adolescence and adulthood, and most dyslexic readers do not 'catch up'. Many young people with dyslexia develop compensatory reading strategies to circumvent their reading difficulties, but they continue to lag behind their peers, especially in spelling and reading speed. Spelling appears to be a major problem for adults with dyslexia. Follow-up of the reading-disabled Isle of Wight sample at 44 years of age shows that more than three-quarters showed significant problems with spelling (with spelling scores 2 s.d. below the mean) compared with peers (Maughan 2009). Slow reading speed is typical of adults with dyslexia. Another consistent finding in research is that adults who were diagnosed with dyslexia in childhood continue to have impaired performance on phonological decoding tasks, indicating that the core cognitive deficits of dyslexia are persistent (Vellutino 2004). There is little research on psychosocial adjustment in adults with dyslexia.

\section{Clinical encounters}

The following anonymised case histories are typical of children presenting to psychiatrists with problems related to dyslexia. 
Case history 1: Apparent auditory and visual hallucinations

A boy aged 8 years 1 month was referred by his general practitioner for 'hearing voices'. He was said to hear 'a screaming voice in his brain', so disturbing that he wanted to take it out and stab it. He also claimed that he saw strange creatures in his bedroom, especially an old woman. In the developmental history it was noted that at the age of 3 to 4 years he had difficulty in naming colours. For example, when shown a red block he could not name the colour, but if asked to choose the red block he would hold it up. At this stage he was tested for colour blindness. His preschool teacher complained of his inability to name animals in picture books and was irritated that he did not remember the names after he had been taught them. There were no other developmental problems. The school report indicated that he was very clever in general but 'was failing to make average achievement in areas of literacy'. He had been enlisted in an early literacy support group.

On examination, in the Schonell Graded Word Reading Test his reading age was 6 years (i.e 2 years behind his chronological age). On the Graded Nonword Reading Test he could read no more than two consecutive words correctly. Subsequent psychometric tests carried out by a psychologist showed that his IQ was 130. On the Sight Word Efficiency subtest of the Test of Word Reading Efficiency, he had a standard score of 70, which translates into an age-equivalent score of 6 years 0 months and places him in the 2nd percentile; on Phonemic Decoding Efficiency subtest, his standard score was 69, again putting him in the 2nd percentile, with the age-equivalent score of 6 years 0 months. In short, he was 2 years behind in most areas of reading skills.

The presenting symptoms were thought to reflect the stress he experienced at school over reading. Later he revealed that the voices in his head resembled that of his teacher, who shouted at him during reading lessons. After reading interventions were put in place at school to address his reading difficulties, the voices and visual imagery disappeared.

\section{Case history 2: Comorbid hyperkinetic disorder}

At the age of 11 , a boy was referred because his overactivity and restlessness interfered with learning and behaviour. He was in trouble with the teachers almost every day. He had been identified as having severe dyslexia before referral. He had a statement of special educational needs and psychometric testing carried out by the educational psychologist at age 7 years 4 months showed a reading age of 5 years 6 months. On referral, the child psychiatrist diagnosed hyperkinetic disorder and prescribed methylphenidate. The boy's response to medication and behavioural management was good. He joined college to pursue an advanced course in IT, where he performed extremely well. In accordance with national guidelines (Learning and Skills Improvement Service 2010), the college carried out a formal assessment of his reading difficulties. At the age of 18 years 8 months, the results of the tests were as follows: WRAT-3 Single-Word Reading: standard score 70 (-2 s.d.); TOWRE Sight Word Efficiency: standard score 70 (-2 s.d.); TOWRE Phonemic Decoding Efficiency: standard score 58 (-3 s.d.); CTOPP Phonological Awareness: standard score 70 ( -2 s.d.); TOWRE rapid naming: standard score 55 (-3 s.d.); non-verbal IQ:
115 (+1 s.d.). Thus, his reading abilities continued to be severe and persistent and had been underestimated while he was at school.

\section{Interventions}

Intervention studies in dyslexia may be grouped into two types: those aimed at early prevention of reading difficulties in young children and those that attempt to treat or remediate reading problems in older children. As mentioned before, dyslexia can be reliably identified in the first 2 years of schooling. Several well-designed studies (e.g. Hatcher 2004) have shown that reading interventions for the 'atrisk' population, such as Year 1 (6-year-old) children who are below the 15th to 20 th percentile in reading attainment, produce substantial improvement. However, remediation programmes after the age of 8 or so, i.e. after the child starts to fail at reading, produce relatively poor results. Although the developmental trajectories of individual children vary, in general the gap in performance between average readers and readers with dyslexia tends to persist. In the older group, reading interventions seem merely to stabilise, rarely bringing about total remediation (Torgesen 2005).

There is now an impressive body of literature on the most evidence-based methods of intervention (i.e. 'what works') in dyslexia. However, often it is not reflected in practice. In the UK, the National Literacy Strategy sets out the principles and practice for teaching of reading to all children (Department for Education and Employment 1988). Children who fail to develop sufficient reading skills should be targeted for special reading instruction as outlined in the Early Literacy Support (ELS) programme (Department for Education and Skills 2001). The ELS programme is an intervention for Year 1 children whose reading skills are identified to be below the 25th percentile. They receive additional reading support from the class teacher and a trained teaching assistant. Many children could be expected to make significant progress in reading with ELS-type early interventions (Torgersen 2005). The 'small minority' of children who do not make sufficient progress with ELS (non-responders) receive (or should receive) more individualised interventions such as one-to-one reading programmes (Department for Children, Schools and Families 2010). Although official ELS documents do not specifically mention dyslexia or reading disability, it is highly probable that this 'small minority' would include most children with dyslexia. It is worth noting that children with dyslexia are usually taught in mainstream schools unless there is accompanying comorbidity such as moderate general intellectual disability or severe conduct problems. 
In practice, severe reading difficulties are identified too late, typically not until Year 3 (at about 8 years of age). Although there are government guidelines on the assessment of reading difficulties in adults that indicate which psychometric tests should be used (Learning and Skills Improvement Service 2010), there are no rigorous protocols for assessment in children apart from curriculumbased assessments. This may partly account for the late identification of dyslexia in the UK.

\section{The Rose report}

A recent educational report has clarified the issue of identification and teaching of children with dyslexia. Known as the Rose report (Rose 2009), it recognises that dyslexia 'exists' and may help to lay to rest the long-running debate among professionals, especially those in education, about whether there is a condition called dyslexia. The report goes on to outline a three-step graded approach for identification and assessment of dyslexia. At level 1 the class teacher identifies poor readers, at level 2 the teacher involves an 'appropriately qualified' teacher and/or special educational needs coordinator (SENCO), and at level 3 a comprehensive assessment is carried out and a decision is made about whether the child has dyslexia and if so, at what severity. The report also recommends three graded 'waves' of reading interventions that dovetail with the assessment process. When a school identifies a child with dyslexia, the above special educational provision would be formalised as 'School Action' or 'School Action Plus', depending on the severity of the disorder and the child's response to intervention. If the child continues to make little progress, the school is expected to undertake a statutory assessment of the child's special educational needs (SEN). How these recommendations will translate into practice is yet to be seen.

\section{BOX 10 Do's and don'ts}

- Do routinely screen for dyslexia in children referred to CAMHS (Box 4)

- Do obtain information from multiple sources, especially from teachers: they know more about the child than you do

- Do remember that your primary role is to attend to the child's comorbid mental health difficulties; any reading difficulties should be drawn to the attention of their teacher
- Do not make 'spot diagnosis'; a comprehensive assessment takes time

- Do not assume that all reading underachievement is caused by dyslexia; consider all aspects of the differential diagnosis

- Do not 'prescribe' educational interventions; discuss with educational professionals

- Do not become triangulated in battles between parents and the school

\section{The role of the child psychiatrist}

Dyslexia is primarily a specific learning difficulty but child psychiatrists are bound to encounter it frequently in their work because of its high comorbidity with mental health problems. The condition is often overlooked. Moreover, it is not always identified by teachers before complications set in. Child psychiatrists should be able to identify dyslexia with confidence and draw the school's attention to a child's reading disability. It is important to have a good knowledge of national policies as well as those of local education authorities and to maintain good communication with schools and educational psychology services. Some practical hints for the management of dyslexia and comorbid psychiatric features in children are shown in Box 9.

Child psychiatrists also need to be aware of the widely different approaches adopted by different professional groups and services. In the case of dyslexia, health professionals talk of diagnosis and treatment, whereas educational professionals talk of identification and intervention (British Psychological Society 2005). Psychiatrists tend to subscribe to a 'deficit theory' of dyslexia, whereas others may subscribe to a 'brain difference' theory. Effective inter-agency working necessarily involves accommodating different perspectives and approaches.

\section{References}

Berger M, Yule W, Rutter M (1975) Attainment and adjustment in two geographical areas: II - the prevalence of specific reading retardation. British Journal of Psychiatry 126: 510-9.

British Psychological Society (2005) Dyslexia, Literacy and Psychological Assessment: Report by a Working Party of the Division of Educational and Child Psychology. BPS.

Carroll JM, Maughan B, Goodman R, et al (2005) Literacy difficulties and psychiatric disorders: evidence for comorbidity. Journal of Child Psychology and Psychiatry 46: 524-32.

Catts HW (1993) The relationship between speech-language and reading disability. Journal of Speech and Hearing Research 36: 948-58.

Catts HW, Adlof SM, Hogan TP, et al (2005) Are specific language impairment and dyslexia distinct disorders? Journal of Speech, Language and Hearing Research 48: 1378-96.

Department for Education and Employment (1988) The National Literacy Strategy: A Framework for Teaching. DfEE.

Department for Education and Skills (2001) The National Literacy Strategy: Early Literacy Support Programme. DfES Publications.

Department for Children, Schools and Families (2010) Early Literacy Support (ELS): Frequently Asked Questions (FAOs). What if some children do not make progress? TSO (The Stationery Office) (http:// nationalstrategies.standards.dcsf.gov.uk/node/84906)

Frederickson N, Frith U, Reason R (1997) Phonological Assessment Battery. NFER-Nelson.

Hatcher PJ, Hulme C, Snowling MJ (2004) Explicit phoneme training combined with phonic reading instruction helps young children at risk of reading failure. Journal of Child Psychology and Psychiatry 45: 338-58.

Kaplan BJN, Wilson B, Dewey D, et al (1998) DCD may not be a discrete disorder. Human Movement Science 17: 471-90. 
Learning and Skills Improvement Service (2010) A Framework for Understanding Dyslexia. LSIS (http://www.excellencegateway.org.uk/ page. $a s p x ? 0=124856$ )

Lewis C, Hitch GJ, Walker P (1994) The prevalence of specific arithmetic difficulties and specific reading difficulties in 9- to 10-year-old boys and girls. Journal of Child Psychology and Psychiatry 35: 283-92.

Maughan B, Nesser J, Collishaw S, et al (2009) Persistence of literacy problems: spelling in adolescence and mid-life. Journal of Child Psychology and Psychiatry 50: 893-901.

Pennington BF, Olson RK (2005) Genetics of dyslexia. In The science of Reading: A Handbook (eds MJ Snowling, C Hulmes), pp 453-72. Blackwell.

Pennington BF (2009) Diagnosing Learning Disorders: A Neuropsychological Framework. Guilford Press.

Raban B (1985) Macmillan Graded Word Reading Test. Nelson Thornes.

Reitzel J-A, Szatmari P (2003) Cognitive and academic problems. In Learning and Behavior Problems in Asperger Syndrome (ed M Prior), pp 35-54. Guilford Press.

Rose J (2009) Identifying and Teaching Children and Young People with Dyslexia and Literacy Difficulties: An Independent Report from Sir Jim Rose to the Secretary of State for Children, Schools and Families June 2009. DCSF (http://publications.dcsf.gov.uk/eOrderingDownload/006592009D0M-EN.pdf).

Schonell FJ (1932) Essentials in Teaching and Testing Spelling. Macmillan.

Schonell FJ, Schonell FE (1950) Diagnostic and Attainment Testing. Oliver \& Boyd.

Shaywitz SE, Shaywitz BA (2003) Dyslexia. Pediatric Review 24: 147-55. Shaywitz S (2003b) Overcoming Dyslexia. Alfred Knopf.

Shaywitz SE, Fletcher JM, Holaham JM, et al (1999) Persistence of dyslexia: the Connecticut Longitudinal Study at adolescence. Pediatrics 104: $1351-9$

Snowling MJ, Stackhouse J, Rack J (1986) Phonological dyslexia and dysgraphia: a developmental analysis. Cognitive Neuropsychology 3: 309-39.

Snowling MJ, Stothard SE, McLean J (1996) Graded Nonword Reading Test. Pearson Assessment.

Snowling MJ, Stackhouse J (2006) Dyslexia, Speech and Language (2nd edn). Whurr Publishers

Snowling MJ (2008) specific disorders and broader phenotypes: the case of dyslexia. Quarterly Journal of Experimental Psychology 61: 142-56.

Stanovich KE (1986) Matthew effects in reading: some consequences of individual differences in the acquisition of literacy. Reading Research Ouarterly 21: 360-406.
Stanovich KE (1994) Does dyslexia exist? Journal of Child Psychology and Psychiatry 35: 579-95.

Stothard S, Hulme C (1995) A comparison of reading comprehension and decoding difficulties in children. Journal of Child Psychology and Psychiatry 36: 399-408.

Thambirajah MS, Grandison KJ, De-Hayes L (2008) Understanding School Refusal: A Handbook for Professionals in Education. Health and Social Care. Jessica Kingsley Press.

Thambirajah MS (2010) Developmental dyslexia: an overview. Advances in Psychiatric Treatment 16: 299-307.

Torgesen J, Alaxander AW, Wagner RK, et al (2001) Intensive remedial instruction for children with severe reading difficulties: immediate and long term outcomes from two instructional approaches. Journal of Learning Disabilities 34: 33-58.

Torgesen J (2005) Recent discoveries on remedial interventions for children with dyslexia. In The Science of Reading: A Handbook (eds MJ Snowling, C Hulme): pp 521-37.

Torgesen JK, Wagner RK, Rashotte CA (1999) Test of Word Reading Efficiency (TOWRE). GL Assessment.

Turner M (2003) The Nonword Decoding Test. Dyslexia Institute (http:// www.dyslexiaaction.org.uk/Administration/uploads/Nonword.pdf).

Vellutino FR, Fletcher JM, Snowling MJ, et al (2004) Specific reading disability (dyslexia): what have we learned in the past four decades? Journal of Child Psychology and Psychiatry 45: 2-40.

Vernon PE (1998) Graded Word Spelling Test (2nd edn). Hodder \& Stoughton.

Vincent D, Crumpler M (2006) Hodder Oral Reading Tests. Hodder \& Stoughton.

Wagner RK, Torgesen JK, Rashotte CA (1999) The Comprehensive Test of Phonological Processing. GL Assessment.

Weschler D (2003) Weschler Intelligence Scale for Children, Fourth Edition (WISC-IV). Pearson Assessment.

Weschler D (2005) Weschler Individual Achievement Test, Second Edition (WIAT-II). Pearson Assessment.

Wilkinson GS, Robertson GJ (2006) Wide Range Achievement Test 4 (WRAT 4). Pearson Assessment.

Willcutt EG, Pennington BF (2000) Comorbidity of reading disability and attention-deficit/hyperactivity disorder: differences by gender and subtype. Journal of Learning Disability 33: 179-91.

Williams S, McGee R (1994) Reading attainment and juvenile delinquency. Journal of Child Psychiatry and Psychology 35: 441-56.

Young D (1978) SPAR Spelling and Reading Tests. Hodder \& Stoughton.

\section{MCO answers \\ $1 d \quad 2$ e $3 d \quad 4$ e $5 c$}

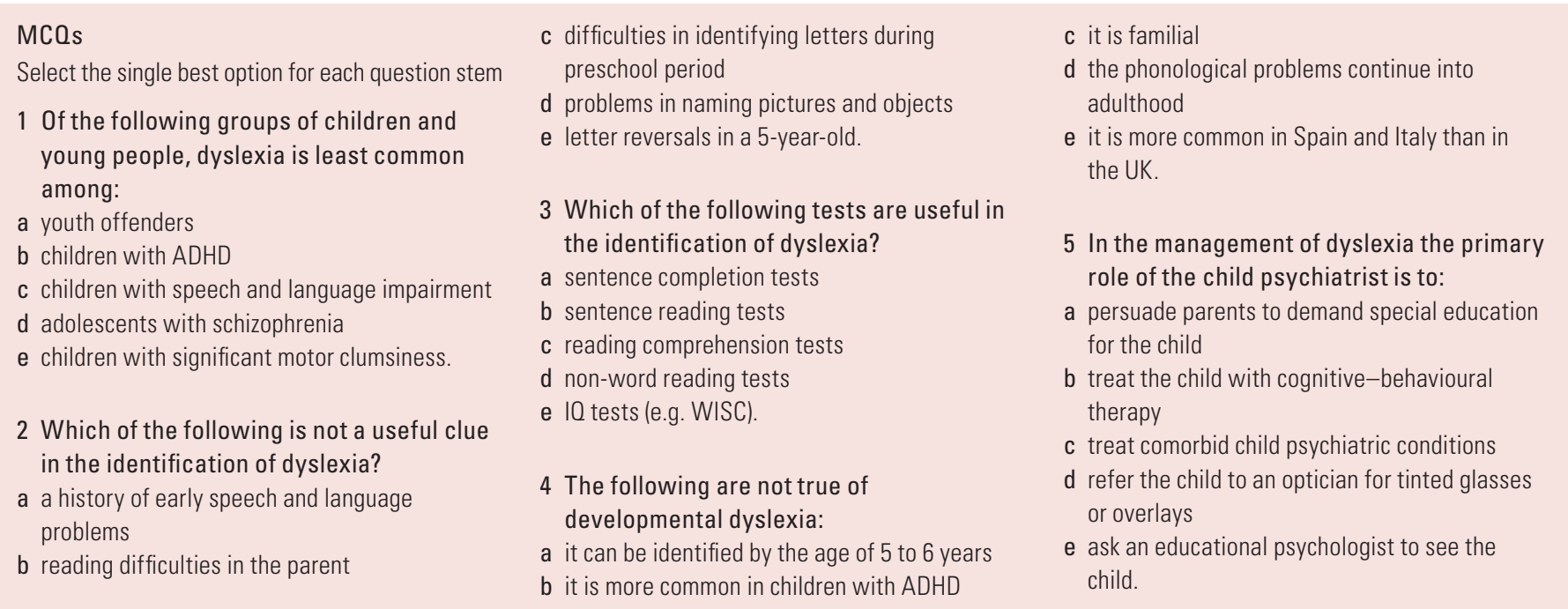

